\title{
Plano de imanência e linguagem: a distância daquilo que "podemos" no campo das práticas corporais de movimento
}

\author{
Immanence and language plan: what may be able to be done in the bodily movement \\ practices field

\section{Plan de inmanencia y lenguaje: la distancia de lo que "podemos" en el campo de las prácticas corporales de movimiento}

Marcelo Adolfo Duque Gomes da Costa ${ }^{a, *}$ (D) , Felipe Quintão de Almeida ${ }^{a}$

Palavras-chave Epistemologia; Desejo; Potência; Corpo.

\section{Keywords}

Epistemology;

Desire;

Power;

Body.

Palabras clave

Epistemología;

Deseo;

Potencia;

Cuerpo.

\begin{abstract}
RESUMO
A partir do conceito de imanência em sua leitura deleuziana, este trabalho objetivou pensar a criação de si como forma de afirmar nossa existência e nosso desejo. O exercício analítico realizado discutiu o aspecto problemático de se justificar a linguagem por seu caráter hermenêutico e seus reflexos em nossa potência de agir. Esse é o resultado de uma produção subjetiva que, ao capturar o desejo, nos distancia daquilo que "podemos" e acaba por diminuir nossa capacidade de ação no mundo das práticas corporais de movimento.
\end{abstract}

\begin{abstract}
Based on the concept of immanence in its Deleuzian reading, this work aimed to think about the creation of ourselves as a way of affirming our existence and our desire. The conducted analytical exercise discussed the problematic aspect of justifying language by its hermeneutic character and its reflexes on our power to act. This is the result of a subjective production, by capturing the desire, that distances us from what may be able to be done and ends up decreasing our capacity for action in the world of body movement practices.

RESUMEN

Partiendo del concepto de inmanencia en su lectura deleuziana, el objetivo de este trabajo es pensar "la creación de si" como una forma de afirmar nuestra existencia y nuestro deseo. El ejercicio analítico realizado discutió el aspecto problemático de justificar el lenguaje por su carácter hermenéutico y sus reflejos sobre nuestra capacidad de actuar. Ese es el resultado de una producción subjetiva que, al capturar el deseo, nos aleja de ese que "podemos" y acaba por disminuir nuestra capacidad de actuación en el mundo de las prácticas corporales de movimientos.
\end{abstract}

aUniversidade Federal do Espírito Santo, Programa de Pós-graduação em Educação Física. Vitória, ES, Brasil.

Autor correspondente:

Marcelo Adolfo Duque Gomes da Costa.

E-mail: orphencelo@gmail.com 


\section{INTRODUÇÃO}

Este é um trabalho que está inserido no contexto da tese de doutorado intitulada "Educação física, corpo e linguagem: a resposta culturalista a partir da vida em sua desmesura", cujo objetivo foi o de pensar elementos que impactam na produção de nossa subjetividade, mais especificamente, os condicionantes que nos tecem quando nos mobilizamos e colocamo-nos perante o mundo ao ser envolver com as práticas corporais de movimento. Iremos, nesse artigo, operar com a ideia de plano de imanência em seu recorte deleuziano a fim de pensar a criação de si enquanto a afirmação da nossa existência e do nosso desejo. Procuramos discutir quais elementos nos distanciam daquilo que "podemos" e dificulta a construção de um plano de imanência a partir das práticas corporais de movimento. Compreendemos a imanência como superfície que permite uma ação que toma para si a potência de criação. Por aquilo que "podemos", nossa referência é a pergunta formulada por Espinosa sobre "o que pode o corpo", segundo a qual devemos buscar a efetuação da nossa existência via a tomada da potência de criação em nós, ou seja, é sermos os agentes produtores de nossa existência ao agirmos para a efetuação de nossa desestratificação. É, como veremos mais adiante no texto, estar preenchido por mais potência de agir do que padecer.

Como desafios para a criação de si, temos elementos que promovem a captura do desejo, processo de captura que acaba por nos afastar daquilo que "podemos". Para o campo da educação física esses afastamentos resultam de um determinado entendimento de linguagem que, ao valorizar em demasia a significação, a capacidade de dizer "o mundo", nos afasta da possiblidade de produção da eternidade na existência, pois estou sempre preso às possibilidades de significação das minhas ações.

O texto está organizado em três sessões: na primeira, situamos nosso objeto; na sequência, apresentamos nosso entendimento do plano de imanência e do que estamos tratando quando fazemos referência a captura do desejo; por fim, discutimos como uma determinada forma de se compreender a linguagem acaba no distanciamos daquilo que "podemos" ao valorizar em demasia os processos de significação.

\section{PLANO DE IMANÊNCIA E A CAPTURA DO DESEJO}

Deleuze e Guattari, em "O que é filosofia?", destacaram que o plano de imanência não é um conceito nem o conceito de todos os conceitos. $O$ plano de imanência é um gigantesco tear, que faz e desfaz o pensamento. O plano de imanência é o mar, em que queremos navegar, o deserto que queremos atravessar. Nós não o vemos, mas ele está lá, esperando para ser traçado, vivenciado, percorrido. Ele oferece um mapa, mas não um caminho, nem uma direção. E a composição do plano é importante porque, como destacam Deleuze e Guattari (2010, p. 45), “[...] a filosofia é um construtivismo, e o construtivismo tem dois aspectos complementares, que diferem em natureza: criar conceitos e traçar um plano". Se os conceitos são ferramentas criadas para resolver problemas, eles habitam o plano de imanência, onde esses problemas colocam-se. As coordenadas intensivas dos conceitos deslocam-se nesse platô diagramático que é o plano da imanência tecido por Deleuze e Gattari. Os conceitos são acontecimentos ${ }^{1}$ que têm no plano de imanência seu horizonte e é ao potencializar essa ressoante relação que se possibilita traçar dar mais consistência possível aos nossos planos imanentes.

É pelo plano de imanência que orientamos o nosso modo de pensar; ele é o primeiro recorte do caos, e é ele, o caos, que opera as conexões entre os inúmeros conceitos que habitam o plano de imanência. E por terem essa conexão com o caos que é preciso assumir que o plano deve ser fluído. Plano, conceitos e o caos ajustam-se mutuamente. É nesse processo de se traçar o plano que se faz possível envolver a velocidade infinita dos conceitos. Para Deleuze e Guattari (2010), a filosofia cria conceitos para enfrentar o caos, ela precisa colocar-se como tarefa construir um plano que dê conta dessa responsabilidade sem perder o infinito. Traçar o plano da imanência é habitar um mundo em que o movimento tomou conta de tudo. O plano de imanência não oferece verdades fixas, somente diagramas de intensidades.

O plano da imanência é esse contínuo intervalar entre a transcendência e o caos. Segundo Gil (2008), para se traçar o plano da imanência é preciso entrar no tempo da imanência; e esse tempo é aiônico. Ele é um tempo de fundo, pois sustenta tudo o que se move e se desloca, tempo contínuo e imóvel, alterando-se a uma velocidade infinita e por isso não se move senão em uma lentidão infinita. O tempo assim compreendido configura-se como uma lentidão ontológica que abarca virtualmente todos os tempos (passado, presente e futuro), uma vez que, na sua lentidão contínua, cada acontecimento tem sempre o mesmo tempo que se insere na espessura da imensidão do plano. Esse é o tempo da imanência; ele não passa; no entanto, ele não é uma espécie de eternidade que sobrevoa, imóvel, a passagem do tempo, não há um além nem um detrás.

Gil (2008) irá destacar que o plano de imanência implica uma série de experimentações e o seu percurso invoca meios pouco confessáveis, pois não seriam, por assim dizer, muito "racionais" e razoáveis. Isso porque é preciso realizar o exercício de pensar a partir de uma tênue e perigosa linha em que se faz necessário destruir

1 Ao se referir ao conceito de acontecimento, o intuito de Deleuze é demarcá-lo como um efeito de superfície, um incorporal, uma "quase-causa", alguma coisa que acontece e que, por sua vez, não se reduz nem às coisas nem às proposições, mas só podendo ser apreendido no instante mesmo em que acontece. 
os estratos ${ }^{2}$ do bom senso. Descontruir o pensamento normalizado e sair da doxa ao se lançar no caos para nele operar; esse primeiro corte é traçar o plano de imanência.

Traçar esse primeiro corte para sair da doxa implica realizar uma violência à existência comum. Esse mergulho no caos pode ser, destaca Gil (2008), perigoso. Isso porque traçar o plano imprime ao pensamento um movimento intensivo, desmesurado e isso o leva aos limites de sua própria potência. O campo dessa desmesura lhe é desconhecido e penetrá-lo exige um movimento duplo: ao mesmo tempo em que se entra em um espaço que atrai para si o mundo inteiro, mas um mundo caótico, sem nexo e sem referências, projeta para fora de si tudo que não é ele. Essa desconstrução egoica permite a capilarização dos mais diversos devires que passaram a ter um campo mais poroso para sua circulação.

Essa experimentação que é traçar o plano de imanência tende a aproximar-se da linha fronteiriça que separa a destruição dos estratos pelo caos e o apelo fortíssimo de outra reterritorialização, processo que permitirá, segundo Gil (2008), o nascer de uma nova transcendência na imanência. Isso porque ela não está à procura de um fora para sua realização, mas a transcendência ocorre na atualização do virtual, ou seja, ocorre na experimentação, quando aquilo que é virtual, essa nossa potência de criar existência em nós, toma o mundo via nossa ação perante a ele. Esse espaço entre o caos e a transcendência é infinito, pois o infinito vem do caos e com ele se construirá o plano absoluto, o horizonte absoluto e infinito do plano de imanência. Esse espaço entre, em que será traçado o plano, é infinito porque é ao mesmo tempo caotizante e capaz de produzir a consistência de que o plano precisa para os outros conceitos ficarem de pé para que possam, assim, ressoarem e combinarem- se.

Traçar para si o campo da imanência é dar consistência às nossas potencias de agir. Quanto mais condições de abertura do corpo ${ }^{3}$ produzimos, mais alargadas são as possibilidades de ação no mundo por diferentes vias. Como destaca Gil (2008), um compositor constrói um plano a partir de sons; o escritor tem na escrita o elemento de sua experimentação; o pintor vale-se das cores e dos espaços. Se consigo traçar o campo da imanência a partir das minhas práticas corporais, é possível, por meio das experimentações, produzir uma relação mais intensiva, a partir também de

2 Estamos, a partir de Deleuze, entendendo estrato como os processos de sedimentação pelas quais passa nossas subjetividades e geram uma rigidez no qual o homem pode se fixar e despotencializar o seu fluxo intensivo.

3 Para Gil (2004, p. 26) abrir o corpo é “[...] abrir o espaço de agenciamentos de fluxos de intensidades, para estes fluam segundo as vias mais adequadas. Agenciar é tecer, atar, anexar, forjar, os dispositivos apropriados às intensidades das forças, numa palavra, é dar consistência à osmose para que não se transforme numa sopa pscicótica". outras ações no mundo. Dessa forma, vamos traçando múltiplos planos de imanência que vão ganhando cada vez mais consistência.

Um importante elemento para o plano de imanência é a captura do desejo e a relação entre eles interessanos, pois ela afeta a construção de uma ação para algo que está além das "minhas propriedades". Isso porque o desejo está estratificado de tal maneira que acaba por ficar atolado dentro do seu processo de captura e isso afeta nossa condição de agir, pois diminui nossa potência.

É a partir de Nietzsche e Espinosa que Deleuze constrói uma concepção do desejo completamente diferente do senso comum; para ele, o desejo sempre foi malvisto e mal compreendido. Deleuze compreende que o desejo não é, ao contrário do que a herança platônica nos mostra, falta. E foi ao longo dos anos ganhando outros adeptos como, por exemplo, a filosofia idealista (Hegel) e a psicanálise (Freud e Lacan). A falta não é parte constitutiva do desejo. Ela não é real, ela foi, ao longo dos séculos, sócio e filosoficamente produzida, fabricada por certos mecanismos de captura, ${ }^{4}$ de poder, que nos farão acreditar que é possível uma vida sob o signo da falta. Antes de ser falta, o desejo é produção; não é carência, mas excesso que ameaça transbordar. Como dizem Deleuze e Guattari (2011), não falta nada ao desejo, não Ihe falta o seu objeto. É o sujeito, sobretudo, que falta ao desejo ou é ao desejo que falta sujeito fixo; o sujeito só é fixado por uma produção subjetiva repressora que produz no vazio sua forma de condução da vida para um estado mais rebaixado e impotente. Nas palavras dos dois filósofos,

A falta é arrumada, organizada, na produção social. É contraproduzida pela instância de antiprodução que se assenta sobre as forças produtivas e se apropria delas. Ela nunca é primeira: a produção nunca é organizada em função de uma falta anterior; a falta é que vem alojar-se, vacuolizar-se, propagar-se de acordo com a organização de uma produção prévia. (Deleuze e Guattari, 2011, p. 45).

O desejo não aprisiona, ao contrário, o desejo liberta porque é o aspecto da força criadora que possuímos. O desejo não carece de objeto. Ele cria o objeto que o preenche como acontecimento de si e a ele nada falta. Ter esse desejo criador como importante elemento para traçar o plano de imanência é relevante para a produção da eternidade na nossa essência. E, baseados em Luiz Fuganti (2013), isso significa produzir mais força na força que me constituí a partir de um uso mais ativo dos nossos afetos. Esse uso ativo dos afetos coloca o desejo em primeiro plano; isso nos leva em um lugar mais adequado para lidar com a desmesura da vida para que possamos traçar nosso plano de imanência,

4 Como exemplo é possível citar a noção de que somos sujeitos incompletos e por isso precisamos buscar algo fora de nós para nossa efetuação. 
cortando a realidade com a experimentação de nossa ação, movidos por esse desejo que é potência criativa e pode romper com o que está normalizado por meio de seu poder agenciador.

Com essa captura do desejo e a situação rebaixada (longe do que "podemos") em que ele nos coloca, ignoramos o movimento mais amplo e extensivo da vida e vamos pulando de efeito em efeito de produções desejantes que estão fora de nós, ou seja, ficamos cada vez mais distantes da possibilidade de sermos criadores de nós mesmos. Assim adotamos, por exemplo, uma determinada prática corporal para atendermos a um certo discurso de saúde (pautado pelo paradigma da atividade física). O consumo dessa prática satisfaz não porque ela é o resultado do meu ganho de potência perante ao mundo, mas, sim, porque enquanto consumidor, dou conta de consumir determinado tipo de saúde e posso posar para o outro tal condição. E, dessa forma, vamos de efeito em efeito reforçando nossa rebaixada condição. E é a reverberação dessa condição rebaixada, que nos afasta daquilo que "podemos", que procuramos debater no próximo tópico.

\section{O "LINGUICENTRISMO" E O DISTANCIA- MENTO DAQUILO QUE "PODEMOS"}

O exercício, agora, será o de debater o aspecto problemático que há em justificar a importância da linguagem por seu caráter hermenêutico (por sua capacidade de se produzir significados) e sua influência em nossa potência de agir e como isso é o resultado de uma produção subjetiva que, ao capturar nosso desejo, nos distancia daquilo que podemos e acabam, por consequência, diminuindo nossa capacidade de ação no mundo.

Para pensar as possibilidades de irmos até o máximo de nossas potências é preciso pensar também nas condições de ação que determinadas abordagens da linguagem proporcionam. Conforme denunciado por colegas desde pelo menos os anos 1990, tem predominado no seio das perspectivas críticas da Educação Física uma compreensão de linguagem que é responsável pela constituição da condição do homem enquanto ser no mundo, ou seja, os processos de subjetivação aos quais somos submetidos tem em seu cerne a linguagem como tendo suma importância. Segundo essa leitura, tudo o que pode ser compreendido se deve apenas a um dos aspectos da linguagem, a significação. De acordo com a interpretação que Bracht e Almeida (2019, p. 9) fazem deste processo,

A pedagogia crítica da Educação Física, no Brasil, padeceu da 'má-compreensão do corpo' criticada por Nietzsche, pois se fundamentou numa logopoiese, em que consciência e linguagem aparecem desencarnadas. No afã de retirar o corpo da 'natureza' e alocá-lo no seio da 'cultura', a pedagogia crítica 'desprezou' o indizível (a 'natureza' do corpo, 'aquilo que pode o corpo', segundo a clássica definição spinozana), em favor de um discurso racionalista e/ou culturalista sobre ele. Para tanto, assumiu um linguicentrismo redescritivo para o qual o corpo não difere do que dizem dele os discursos imperativos de todos os gêneros que moldam seus movimentos. O corpo, assim, é passivo, substância morta, objeto de alguma ação; nada dele devemos esperar para a leitura do mundo.

O linguicentrismo apontado pelos autores destaca uma compreensão da linguagem que a reduz à sua capacidade de se produzir significado, o que explicaria, aliás, o não lugar do corpo no processo de dizer alguma coisa sobre o mundo, já que concebido a partir de sua passividade. Esse modo de entender a linguagem se torna ainda mais contestável se adotarmos a ideia de Gil (1996) sobre o pós-pré-verbal ${ }^{5}$ e como esse tipo de conceito irá ajudar a fomentar a possibilidade de um passado imemorial, ou seja, um passado que nunca se tornou presente; essa compreensão de Gil dá-nos elementos para pensar que nem todos os elementos que compõem a linguagem estão atrelados à palavra ou, mais precisamente, à significação. Claro, isso não quer dizer que esses elementos pré-verbais não recaíram, em algum momento, na palavra, na significação, contudo existem elementos que nunca chegaram a atingir o nível da significação, serão uma massa amorfa de sentido (Gil, 2008), e, ainda sim, fazem parte da linguagem e, por consequência, nos constituem. A linguagem é, portanto, o "mecanismo" que temos para interagir com o mundo. E o que rege minha relação com o mundo? O plano de imanência e o desejo. Eles são a nossa ressonância com o que está ao nosso redor. Nessa relação em que as minhas singularidades se encontram com outras. Quanto melhor conseguir expressar o meu desejo, mais potente minha relação com mundo. Mas como realizo tal construção? Via linguagem. Assim, ela é a expressão do meu desejo, da minha condição de produzir devires. Isso guarda relação com a significação, pois ela é um dos três grandes estratos do desejo (organismo e subjetivação são os outros dois na linguagem deleuziana). Eles são condicionantes a nos afastar do que podemos, pois diminuem nossa potência de agir.

É por haver a tênue relação entre o pré-verbal e o verbal que a linguagem é possível, de maneira que a produção de significado é um resultado do processo, mas não é o ponto final. A significação está no meio do caminho. Ao valorizar em demasia a significação, aquilo que Betti (2006) chamou de terceiridade ou, então, a linguagem nominal (Fensterseifer e Pich, 2012), a pedagogia crítica nos afastou da possiblidade de produção da eternidade na existência, pois estou sempre preso as possíveis significações que minhas ações podem produzir. Mais do que justificar a função da linguagem por sua capacidade de produzir significados, entendemos que

5 Sobre essa posição de Gil, consultar Almeida (2012), Costa (2014) e Costa e Almeida (2018). 
ela deve ser compreendida por sua condição de produzir intensidades, devires. A possibilidade da efetuação da nossa existência é composta por elementos muito mais diversos do que aqueles a atingir o nível da significação. As intensidades que os atravessam são a ressonância da nossa produção desejosa e são elas a nos pôr em movimento. A significação é mais um elemento a compor esse movimento, não é sua causa, muito menos sua justificativa final.

A linguagem é possível graças ao acontecimento e ele tem em seu pano de fundo não apenas o sensível, mas também o insensível, pois, como argumenta Orlandi (2004), para tomar os corpos intensivos como possibilidade, temos de levar em conta também a outra face da produtiva conectividade desejosa, sua face improdutiva. O fluxo intensivo ocorre tendo como pressuposto do funcionamento desejoso sem uma finalidade, pois os corpos intensivos potencializam uma conectividade desejosa que é, por assim dizer, cega.

A concepção da linguagem aqui defendida afeta o que podemos construir a partir de nossa relação com o mundo. Uma compreensão de linguagem que enfatiza os processos de significação está relacionada, para usar os termos de Espinosa, com nossas potências de padecer, nossa impotência, isto é o mais baixo grau de nossa potência de agir. A referência é a leitura que Deleuze fez da filosofia espinosana a partir da pergunta do que pode o corpo. Para o filósofo francês, o que pode um corpo é a natureza e os limites de seu poder de ser afetado. Dois importantes elementos que compõem nosso poder de sermos afetados são a força ou a potência de padecer e nossa força ou potência de agir. Por potência de padecer, entende-se que nosso poder de ser afetado está preenchido por afecções passivas, ou seja, quando sentimos o efeito de um corpo sobre o nosso. A ideia de afecção ${ }^{6}$ não expressa a causa, a natureza do corpo exterior. O que é indicado, segundo Deleuze (2017), é a constituição presente de nosso corpo, o jeito pelo qual nosso poder de ser afetado acha-se preenchido naquele momento. Nessa esteira, a afecção de nosso corpo é somente uma imagem corporal, a ideia de afecção, assim como ela está em nosso espírito é, para os termos espinosistas, uma ideia inadequada ou uma imaginação. Nas palavras de Deleuze,

De fato, uma ideia que temos indica o estado atual

6 Afecção aqui é usada nos termos espinosanos. Segundo Ramond (2010, p. 16), afecção e modos são definidos praticamente de formas simultâneas e "[...] caracterizam fundamentalmente como realidades dependentes de outras realidades. Mais precisamente, a afecção designa ao mesmo tempo o que determina e o que altera". Ainda conforme Ramond (2010), afecção quase sempre caracteriza o corpo humano. Nosso corpo é constantemente submetido a ações das outras coisas, reflete-as, com efeito, em certa medida: esquenta com o calor, fere-se com o que é duro. da constituição do nosso corpo; enquanto nosso corpo existe, ele dura e se define pela duração; seu estado atual não é, portanto, separável de um estado precedente como o qual ele se encadeia numa duração contínua. Por isso, toda ideia que indica um estado do nosso corpo está necessariamente ligada uma outra espécie de ideia que envolve a conexão desse estado com o estado passado [grifo do autor]. (Deleuze, 2017 p. 245).

Deleuze procura, assim, destacar que nossos sentimentos, por si mesmos, são ideias que abarcam a conexão concreta do passado com o presente em uma duração contínua, ressaltando, assim, a dimensão aiônica da linguagem ${ }^{7}$ em seus elementos de um passado que nunca será presente e, portanto, não irá atingir necessariamente o nível na significação.

A ideia inadequada é uma ideia de que não somos a causa, mas ela é a causa de um sentimento de que não somos a causa adequada e tal sentimento seria, necessariamente, uma paixão. Segundo Deleuze (2017), somos desde o início de nossa existência preenchidos por ideias inadequadas e sentimentos passivos. A contrapelo disso, uma ideia adequada seria aquela de que seríamos causa de um sentimento, pois ele seria fruto de nossa ação. As ações nascem somente de ideias adequadas, ao passo que as paixões dependem apenas das ideias inadequadas. O filósofo francês, à luz dos escritos de Espinosa, dirá que conforme nosso espírito tem ideias adequadas, ele mostra-se ativo em certas coisas, e na medida em que ele tem ideias inadequadas, mostrarse-á passivo em outras. Deleuze também lembra que adequado e inadequado, além de serem qualificações de ideias, são também qualificações de causas; seríamos, dessa forma, a causa adequada de um sentimento que se segue de uma ideia adequada que temos.

Se nossa existência é preenchida por sentimentos passivos, é possível, à medida em que ela dura, ser tomada também por afecções ativas, ainda que tal preenchimento ocorra de maneira parcial. Tal possibilidade seria a força ou potência de agir, ou seja, a potência de agir própria da alma, para usar os termos de Espinosa. É a partir dessa relação entre a potência de padecer e de agir que se constitui o poder de ser afetado e esse poder se mantém constante independente da proporção das afecções passivas e das afecções ativas. Dentro de um mesmo poder de ser afetado, podemos constituir proporções passíveis de variação de afecções passivas e ativas. Quando chegamos a produzir afecções ativas, as passivas reduziriam na igual proporção. Caso permaneçamos em nossas afecções passivas, nossa potência de agir é "impedida" tanto quanto. Deleuze

7 Por dimensão aiônica da linguagem, a referência é ao tempo aiônico. Os aspectos da linguagem que guardam relação com outra dimensão do tempo que não a cronológica e, os quais poderão ser resgatados (ou não) a partir de nossas ações. 
(2017) afirma que a potência de padecer nada exprime de positivo. Padecemos por algo que está exterior a nós; ela representa a finitude, a limitação de nossa força de agir. Na medida em que somos preenchidos por afeç̧ões passivas permanecemos imperfeitos, impotentes, separados de alguma forma de nosso grau de potência, separado do que "podemos". As afecções passivas preenchem nosso poder de sermos afetados, porém, antes, elas o reduzem ao seu grau mínimo, restringindo-nos daquilo que podíamos, ou seja, reduzem o alcance de nossa potência de agir. Por exemplo, quando alguém decide começar a correr na praia movido pelo discurso da atividade física, ela se move a partir uma ideia inadequada. Assim, o seu ato de correr é, a princípio, percorrer distâncias em um determinado tempo; seu encontro é com o relógio, não com a praia. Sua potência de agir (em um grau mínimo) irá circular por sedimentar intensidades relacionadas, majoritariamente, ao ganho de performance. Ignorando ou "impedindo" que outros tipos de intensidades circulem. Contudo, é possível que esse grau de potência de agir ganhe mais proporção. Ao afirmar que não sabemos o que pode um corpo, Espinosa está apontando para o fato de não podermos saber, de antemão, de quais afecções somos capazes, desconhecemos, assim, qual a nossa potência de agir. E, sem dúvida, destaca Deleuze (2017), nunca o saberemos se não tentarmos exercer nossa potência de agir via a produção de devires ativos mobilizados por nossa produção desejosa. $O$ encontro pode ser não apenas com o relógio, mas também com a praia.

Ao valorizar em demasia a significação como o ponto final da linguagem, damos mais espaço para nossa potência de padecer, ao sermos preenchidos por mais afecções passivas do que ativas, pois, antes mesmo de agirmos, ela leva-nos ao grau mais baixo de nossa potência de agir. Isso acaba por nos afastar daquilo que podemos nos colocando com menos condição de enfrentar essa sólida estrutura de produção de estratificação que aposta no esmagamento das singularidades, por meio de uma implacável e normalizadora rotina. Encontrar as linhas de fuga exigem o desenvolvimento de uma "musculatura afetiva", uma sensibilidade que de conta de encontrar e/ou produzir rachaduras nesse maciço altamente estratificado que nossa vida se tornou. Isso significa explorar as experimentações de cada prática corporal naquilo que ela nos oferece, encontrar uma zona confortável e, a partir das linhas de fugas possíveis, construir um "pedacinho novo na terra". Como destaca Correia (2017, p. 84), é

[...] necessário compreender que as práticas corporais em seu nível mais fundamental dizem respeito a como os corpos são afetados e quais são os afectos produzidos e circulados a partir destas afecções. Essa compreensão convida a EF prestar mais atenção nos corpos envolvidos no momento dos encontros que as práticas corporais possibilitam sem a busca de interpretá-las como uma função ou expressão de algo mais amplo ou exterior às próprias práticas corporais.

Há no campo da educação física trabalhos que procuram, cada um a sua maneira, discutir os limites do linguicentrismo. Dentre os quais podemos citar (Betti, 1994, 2006; Bracht, 1999, 2019; Almeida, 2012; Pich et al., 2015; Fensterseifer e Pich, 2012; Costa, 2014; Correia, 2017; Bracht e Almeida, 2019, Almeida e Eusse, 2020). Eles buscam trazer abordagens que estão com o corpo; guardadas suas especificidades, de maneira geral são aproximações da ideia de se tomar para si o aumento de nossa potência de agir, para usar os termos do Espinosa. De nos preenchermos mais da potência de agir do que a de padecer. $O$ intuito é o de apostar no movimento, via as práticas corporais, como esse importante aspecto da vida, e reconhecer nele uma forma de sua efetuação. Essa é uma relevante iniciativa, pois implica na valorização da vida, cuja desmesura não está somente nas medidas validadas por um determinado tipo de racionalidade cientificista. Há mais em jogo do que números e quantificações podem mostrar-nos. $\mathrm{E}$ há também mais em jogo do que uma concepção de linguagem "linguicentistra" consegue representar. A intenção desse trabalho foi o de apresentar alguns. Por isso é importante trazer à baila autores como Gil e Deleuze, para ter ainda mais elementos para essa árdua tarefa que é a criação de si.

\section{CONCLUSÃO}

Promover o desejo enquanto força constitutiva da nossa existência deveria ser um dos deveres dos mais diversos processos educativos. Para a educação física essa promoção deve dar-se via o estímulo da experimentação, pois se o desejo não é algo no interior do inconsciente, então ele é acima de tudo social, produz-se no encontro com outros corpos. Trata-se, portanto, da intensificação e da promoção mútuas. Trata-se de proliferar ação, de proliferar o desejo: o desejo prolifera o pensamento, o pensamento faz crescer a ação. Isso nos ajudaria a tecer a arte da criação de si, ou seja, a fomentar esse contínuo intervalar entre a transcendência e o caos para traçar o plano de imanência que só pode acontecer por conta da abertura do corpo, via as experimentações.

Prezar pela intensidade que nos atravessa e ter as condições de traçar alguns caminhos que aumentam nossa potência é prezar também por nossa condição de agir no mundo, pela produção de nós mesmos. Por isso, traçar o nosso mapa de intensidades é valorizar os afetos que nos atravessam. Somos mais potentes quanto mais afetos somos capazes de integrar, de mobilizar. Conhecer seus caminhos, suas formas de circular, é valorizar e potencializar o nosso conhecimento, pois como diz Espinosa, o conhecimento é um poderoso afeto. Quanto mais conhecimento tenho sobre meu vértice afetivo, quanto mais alargado for meu conhecimento sobre ele, maior minha capacidade de pensar. É compreender, por exemplo, de que forma estou sensibilizado para a prática do basquete, que tipo de experimentação 
posso a partir dele? É possível produzir um mapa de intensidade semelhante em outra forma de ação no mundo? Posso encontrar outro tipo de experimentação dentro dessa minha ação ao jogar o basquete? E, assim, vamos mapeando, fomentando nossos mapas intensivos ${ }^{8}$ ao compreender aquilo que nos mobiliza e aquilo que não. Esse processo pode nos levar a outras experimentações que pode, ou não, se aproximar daquela que experimentamos a partir da prática do basquete. Conhecer é poder fazer parte da relação entre o todo e as partes. Por isso precisamos procurar sempre pela causa adequada, questionando os porquês de algo ter se tornado o que se tornou. Precisamos ser a causa de nós mesmos.

\section{FINANCIAMENTO}

Fundação de Amparo à Pesquisa e Inovação do Espírito Santo (FAPES). Fundação Estadual de Amparo à Pesquisa do Estado do Espírito Santo. Edital: 124/2014.

\section{CONFLITOS DE INTERESSE} interesse.

Os autores declaram não haver conflitos de

\section{REFERÊNCIAS}

Almeida FQ, Eusse K. Educação física, linguagem, corpo. Rev Bras Educ Fis Esc. 2020;3(3):46-57.

Almeida FQ. Educação Física, corpo e epistemologia: uma leitura com o filósofo José Nuno Gil. Atos Pesqui Educ. 2012;2(2):329-44.

Betti M. Corpo, motricidade e cultura: a fundação pedagógica da Educação Física sob uma perspectiva fenomenológica e semiótica [tese]. Florianópolis: Universidade Federal de Santa Catarina; 2006.

Betti M. O que a semiótica inspira ao ensino da educação física. Discorpo. 1994;3:25-45.

Bracht V, Almeida FQ. Pedagogia crítica da educação física: dilemas e desafios na atualidade. Movimento. 2019;25:e25068. http://dx.doi.org/10.22456/19828918.96196.

8 Por mapa intensivo compreendemos como sendo esse movimento que, a partir da abertura do corpo, temos uma melhor condição de reconhecermos quais mobilizações nossas intensidades produzem em nós mesmos.
Bracht V. A educação física escolar no Brasil: o que ela vem sendo e o que ela pode ser (elementos de uma teoria pedagógica para a educação física). Ijuí: Editora Unijuí; 2019.

Bracht V. Educação física \& ciência: cenas de um casamento (in)feliz. Ijuí: Editora Unijuí; 1999.

Correia ES. Corpo, produção do comum e a potência de movimento: contribuições de Spinoza e Deleuze para o teorizar em educação física [dissertação]. Vitória: Universidade Federal do Espírito Santo; 2017.

Costa M, de Almeida FQ. A educação física e a "virada culturalista" do campo: um olhar a partir de Mauro Betti e Valter Bracht. Corpoconsciência [Internet]. 2018 [citado 2o de abril de 2021];22(1):1-12. Disponível em: https://periodicoscientificos.ufmt.br/ojs/index.php/ corpoconsciencia/article/view/5222

Costa MA. Corpo, linguagem e educação física: o limite culturalista sob a perspectiva do filósofo José Nuno Gil [dissertação]. Vitória: Universidade Federal do Espírito Santo; 2014.

Deleuze G, Guattari F. O anti-Édipo: capitalismo e esquizofrenia. 2. ed. Rio de Janeiro: Editora 34; 2011.

Deleuze G, Guattari, F. O que é Filosofia? Rio de Janeiro: Editora 34; 2010.

Deleuze G. Espinosa e o problema da expressão. São Paulo: Editora 34; 2017.

Fensterseifer P, Pich S. Ontologia pós-metafísica e o movimento humano como linguagem. Impulso. 2012;22(53):2536. http://dx.doi.org/10.15600/2236-9767/impulso. v22n53p25-36.

Fuganti L. Criação de si como obra de arte [Internet]. 2013 [citado 2020 Jul 28]. Disponível em: https://www.youtube. com/watch?v=8jMcywa-HUE\&t=752s

Gil JN. A imagem-nua e as pequenas percepções: estética e metafenomenologia. Lisboa: Relógio d'água; 1996.

Gil JN. Movimento total: o corpo e a dança. Lisboa: Relógio d'água; 2004.

Gil JN. O imperceptível devir da imanência: sobre a filosofia de Deleuze. Lisboa: Relógio d'água; 2008.

Orlandi BL. Corporeidades em minidesfile. Unimontes Cient. 2004;1(1):43-59.

Pich S, Silva S, Fensterseifer PE. Cuerpo lenguage y (bio) política: los giros del cuerpo y su educación en la alta modernidad. In: Galak E, Gambarotta E, editores. Cuerpo, educación, política: tenciones epistémicas, históricas y práticas. Buenos Aires: Biblos; 2015. p. 59-73.

Ramond C. Vocabulário de Espinosa. São Paulo: Editora WNF Martins Fontes; 2010. 